\title{
A Study on Purchase Behavior of Consumer Durable Goods with Special Reference to Tiruvarur District
}

\author{
P.Sathya ${ }^{1}$, Dr.R.Indirajith ${ }^{2}$ \\ ${ }^{1}$ M.Com.,M.Phil.,Research Scholar,Department Of Commerce, Thiru.Vi.Ka.Govt. Arts College, Tiruvarur. \\ ${ }^{2}$ M.Com.,MBA.,M.Phil.,Ph.D.,Associate Professor And Research Supervisor,Department Of \\ Commerce,Government Arts College,Manalmedu.
}

\begin{abstract}
:
The consumer durable goods industry is operating in a highly competitive, complex and rapidly changing business environment. Business leaders of consumer durable white goods organizations know their importance of having ready to access timely, accurate, consistent information and data for the purpose of establishing, nurturing and managing customer relationships across divisions. The research paper deals with the study on purchase behavior of consumer durable goods in Tiruvarur district.
\end{abstract}

Keywords: Consumer Durable Goods, Purchase Behavior, Consumer Buying Behavior, Consumer Durables Market, Consumers Awareness.

\section{Introduction}

India is the second largest consumer market in the world. The Indian consumer profile has been developed and changed in terms of education, income, occupation, and reference group and media habits. There is a shift in consumer brand preference for durables products for the past decade with the influx of modern technology. The consumer buying preferences are rapidly changing and moving towards high-end technology products with acculturation. Products which were once considered luxury items have become a necessity because of the changing lifestyle and rising income levels. With growth in disposable incomes, the demand for high-end products such as television, washing machine, refrigerator, and air conditioners has increased considerably. It is also facilitated by the easy availability of finance and prevalence of nuclear families. Increasing in demand for consumer durable in the market the fall in prices as Indian consumers are continue to attach a high degree of importance to value for money. The consumer is brand-conscious, but not necessarily brand-loyal, and might even pick up a reliable private label if it offers good price and quality values.

Consumer durable penetration is one of the lowest in India and the untapped potential is evidently enormous. Both manufacturers and traders would be compelled to explore every conceivable method to improve operational efficiencies, in order to achieve substantial and profitable business growth. The Indian consumer durables market has undergone a major transformation since the liberalization process, initiated in 1991. The market size, product penetration, the variety and technology of products sold, have all experienced a quantum leap. Improved product choice and decline in real prices, matched by increased consumer incomes have driven the market growth rate to dizzy heights. Now brands are becoming the most valuable assets that businesses can possess. The marketers are facing lot of challenges: regarding differentiation which is valued by the customers. Brands in this context are new business warriors. Brands are wealth generators of the twenty first century. Products are not differentiated in the factories, but brands are differentiated in the customers' mind. Brands are capable of transforming mundane products into objects of desire. Accordingly, the market value of a business is determined by the number and types of brands it holds. Today in a competitive market, the question is about the survival of the company in the market. The answer is survival of companies by branding. The proper strategy of branding planning 
is needed to achieve revenue, sales, quality and market share. A good strategy differentiates one company's brand from the other competitor's brands.

\section{Concept of Marketing}

The term -Marketing $\|$ suggest different meanings to different people; to some it is shopping, to others it is selling and still others understanding it is the activity undertaken by the companies to make an exchange transaction, a accomplish and adding one bring out greater output at a minimum cost. Marketing in its most general definition, - it is the directing of the flow of goods and services from the producer to consumer or users.

\section{Marketing Research}

Marketing research may also be defined as intelligent tool of management or as an investigative arm of marketing manager helpful in planning and controlling marketing operations.

Thus, marketing research has a broad area of application which describes its scope. The main purposes of marketing research to a marketer are planning and control, but one point that must be stressed here that marketer or a marketing manager has always limitations in terms of resources and time. There may be a number of problems or decisions to face and due to the above limitation only critical problems areas should be identified and given priorities for the research.

\section{Consumer Buying Behavior}

The consumer buying behavior can be defined as the way in which consumers or buyers of goods and services tend to react or behave when purchasing products that they like. Buyers tend to exhibit different types of buying behavior when they are in the process of purchasing goods and services and the behaviors witnessed are influenced by the type of product he/she wants to buy.

Consumer buying behavior involves a long process where the buyer has to identify the product, study well its features, the pros and the cons and lastly deciding on whether to purchase it or not. Consumer buying behavior would make a certain buyer to purchase product $\mathrm{A}$ as opposed to product B or whether to purchase a certain product or leave it alone and all that is as a result of the buying decisions made by the buyer as to whether the product suits his/her needs and requirements. The Consumers of goods and services may possess different types of consumer buying behavior that are unique to themselves. The buying behavior of consumer A may be different from those of consumer $\mathrm{B}$ and the difference may vary buying decision made by a consumer. To understand more on this let us give a definition to each of the different types of consumer buying behavior that are associated with different buyers and consumers of products. Indian consumer durable market is well known by the foreign firms who coverage foreign products and technology as per preference of Indian consumer.

\section{Consumer Durable Goods}

Consumer durable goods refer to various devices used in a household kitchen to reduce manual human labour content and to remove the drudgery in working place and to make household activities speedy, tidy and enjoyable. There are, in the present day, a large number and a variety of such household appliances like Air conditioners, Refrigerator, Television, Washing machine and, Wet Grinder. To make life more enjoyable and entertaining, people also own audio and video players, home theatres and music systems. The researcher selected durable goods like Air conditioners, Refrigerators, Television, Washing machine and Wet grinder for the present study.

The share of gold ornaments in durables expenditure was estimated at nearly $24 \%$ in rural India compared to about $20 \%$ in urban India. Refrigerator had a share of over $21 \%$ in urban India, compared to $9 \%$ in rural India. The share of motorized two-wheelers was about $12-14 \%$ in both sectors. Household Consumption of Various Goods and Services in India.

\section{Shopping Pattern Of Consumer Durables}

The present world is changing fast. India is no exception. Especially after the opening up of the economy, the pace of change that India and its people are experiencing in their socio-cultural milieu is mind boggling. India, with its wide diversity, offers a fascinating scope to study the host of changes which developmental activities have brought about in its social and economical framework.

\section{Need Recognition}

Need recognition means awareness of a want or a desire. A buying process starts with the need arousal. A need can be activated through internal or external stimuli. The basic needs of a man arise to a particular level and become a drive and he knows from his previous experience. This is a case of 
internal stimulus. A need can also be aroused by an external stimulus such as the sight of a new product in a shop while purchasing the usual product.

\section{Product Awareness and Information Search}

In this stage, the consumer enters a stage of active information search to get product awareness. He/she tries to collect more information about the product, its key attributes, and qualities of various brands and about the outlets where they are available.

\section{Evaluation and Intention}

Once interest in a product is aroused, a customer enters the subsequent stage of evaluation and intention. The evaluation stage represents the stage of mental trial of the product. During this stage, the consumer assigns real-time value-weights to different products/ brands on the basis of accumulated stock of product information and draws conclusions about their relative satisfaction giving potential value. After this evaluation, the consumer develops the intention either to purchase or reject the product. The final purchase will however depend on the strength of the positive intention, that is, the intention to buy.

\section{Purchase}

It is the terminal stage in the buying decision process that completes a transaction. It occurs either as a trial or adoption. If a consumer is buying something for the first time, from the behavioral view point, it may be regarded as trial. This trial enables him to accumulate experience about the product purchased. (Beatty et al : 1987). If this experience is positive in terms of satisfaction derivation then repeat purchases may occur. However repeat purchases will occur only when he is satisfied with the performance. But the possibility of trial purchase is available. In the case of durables like refrigerator, air- conditioner and microwave oven, trial purchase is not possible because, once a product is purchased it has to be adopted and repeatedly used.

\section{Post Purchase Behaviour}

Post Purchase behaviour refers to the behaviour of a consumer after his commitment to a product has been made. It originates out of consumer experience regarding the use of the product and is indicated in terms of satisfaction. This behaviour is reflected in repeat purchases or abstinence from further purchase.
Post Purchase behaviour refers to that behaviour exhibited after the purchase decision. The goal of consumers' ${ }^{6}$ decision system lies in consumption and consumption occurs during the post-purchase phase. Thus purchases are only "means to an end the end being the attainment of benefits from consuming the product or service. From marketers ${ }^{\text {ee }}$ perspective, long term success flows from having consumers experience satisfaction during the post-purchase phase. The post-purchase processes account for two major activities, consumption and disposition. Trashing, saving and selling the product are the three major options of product disposition.

\section{Need For The Study}

The country is witnessing the creation of many new markets and a further expansion of the existing ones. With over 500 million people moving up from the category of rural poor to rural lower middle class between 2007 and 2017, rural consumption levels are expected to rise to current urban levels by 2020. The Consumer durables products purchased by consumers that are manufactured for long-term use, as conflict too many goods that are proposed for use in the short term. Consumer durables are intended to tolerate regular usage for several years or longer before replacing the required consumer product. Every household contains at least a few items that may be properly considered to be of a consumer durable nature. A combination of consumer depends upon lifestyles; income, product awareness and pricing have been instrumental in changing the pattern and amount of consumer expenditure leading to strong growth of consumer durables industry. Due to demographic; socio economic and cultural status of impact the buying behavior of consumers. It is fact that in these aspects the differences are decreasing progressively. Till these differences remain, the groups require different treatments. These allied questions call for scientific enquiry to find out the prospects of consumer behavior towards durable goods. Against this background, a humble attempt is made in this study with reference to Tiruvarur District of Tamil Nadu state in India.

\section{Nature of The Study}

This is an empirical study on the relationship between consumer behavior and choices of variables in the present study were selected mainly on the basis of consumer durable goods, isolated studies on consumer durable goods and demographic characteristics of the durable products. 
The study involves three stages. The first stage was to define the study areas, selecting the respondents, and defining the independent variables. The second stage was to conduct a field work for collecting the information. The third stage was making to a statistical analysis and interpretation.

\section{Research Gap In The Literature}

The literature review is a significant step in each and every research process. Review of earlier studies discloses the works and studies done by individual researchers and institutions help to establish further the need for the study. The researcher has reviewed 75 studies, which include 60 Indian journals and 15 international journals were collected. The previous studies identified important gap that will be explored in this thesis. In this research special attention being given to the marketing strategies adopted by the manufacture for effective reach is also done. The various studies related to consumer behavior, rural market and urban market have been conducted by different social scientists at micro as well as macro level in India and abroad. The present study was covered the Consumer Behavior towards consumer durable goods. But no study was made in purchase Behavior towards consumer durable goods.

James U. Mcneal, Chyon-Yeh, (2016) have searched that examining - Tolerance for Unethical Consumer Behaviour Provides a Key Insight to how People Behave as Consumers Worldwidell. In this study, consumer reactions to unethical consumer behaviour scenarios are investigated using sample data from Austria, Brunei, France, Hong Kong, the UK, and the USA. Nationality is found to be a significant predictor of how consumers view various questionable behaviours. Gender is not a significant predictor, while age and religious affiliation are found to be significant predictors of consumer ethical perceptions.

Krishna Mohan Y. and Naidu, (2015) have identified -An Evaluation of Consumer Awareness in Rural Marketsll. This paper deals with the extent of awareness in rural markets of India. It presents the - Goldll available in this steadily growing market which has been going great guns since the 1980's and now bigger than the urban market for both FMCG's and durables, the former with 53 per cent share and the latter with 59 per cent of total market.

Paul Harrison and Robin Shaw, (2014) have contributed -Consumer Satisfaction and Post-
Purchase Intentionsll. An Exploratory Study of Museum Visitors. This paper examines the relationship between consumer satisfaction and subsequent intentions in the museum context as well as the moderating influence of demographic characteristics such as gender, age and education in that relationship. The relationship between satisfaction and a range of service elements, overall satisfaction with the experience and intentions was investigated. Museum marketers can profit by examining the 'Value chain" of museum experience outlined in the model presented, especially the greater likelihood of consumers recommending the experience to others than making a repeat visit themselves, and by investigating segment differences beyond those reported here.

Sudarshan R. and Sridhar, (2013) have conducted -Impact of Consumer Involvement of Buying Decision - A Conceptual Frame-Work. Consumer involvement refers to the intensity of interest with which consumers approach the market place. It is related to the consumers' values and self-concept which influence the degree of personal importance ascribed to a product or situation consumer involvement varies Krishna across different individuals, product, brands and situations.

Alet C. Erasmus, Meriam M. (2012) has focused on the -The Paradox of Progress: Inexperienced Consumers' Choice of Major Household Appliances\|. The results supported the initial notion that limited consumer socialization may result in, and even necessitate inexperienced consumers" reliance on surrogate indicators of quality, such as price, brand name and store image, as compensation for lack of appropriate product knowledge unfortunately the use of surrogate indicators of quality does not necessarily imply informed, responsible buyer behaviour.

Christopher P. Blocker, Daniel J. Flint, (2007) has analyzed that -The Relationship between Satisfaction, Loyalty and Buying Intention Perceived by Spanish Consumers. Scale development was based on the review of the most relevant literature regarding food marketing and agribusiness. Data were collected through a structured questionnaire. A structural equations model was applied to analyze the relationships among consumer satisfaction, loyalty and buying intention. The results show that a higher satisfaction leads to greater levels of loyalty and buying intention of the consumers.

SCOPE OF THE STUDY 
The study aims at focusing study on purchase behavior of consumer durable goods in Tiruvarur district. Researcher limits its scope to selected consumer durable such as Air conditioners, Refrigerator, Television, Washing machine and, Wet Grinder. Hence, it is necessary to concentrate on consumers' perception, consumers' pre-purchase and post-purchase behavioral activities. There are many sides of consumer behaviour that possibly need elaboration and how ever this study concentrates on individual consumer purchase behaviour regarding the purchase of consumer durable goods already stated. This research study is exploratory in nature. Moreover, the area of the study is confined to Tiruvarur district. The study focuses on the durable products in urban and rural area in seven Taluks in Tiruvarur district.

The Indian economy is basically divided into urban and rural. Rural sector is now balanced for contribution a vast potential to marketers and promises to be an opportunity for which are to be grab by surmounting challenges and threats. To surveys and audits for a number of consumer products and services have, over the years, clearly highlighted the emerging importance of the rural and urban sectors. There have been less focused studies analyzing the consumer durable market in the background of changing scenario of rural and urban markets. And there have been less attentiveness on consumer behavior studies. This present comparative study is an attempt to fill this void in research on rural and urban markets. This study is confidential to rural and urban areas in Tiruvarur District of Tamilnadu, India.

\section{Problems of The Study}

The study of behavioral aspect of consumers is great importance for marketers and this knowledge is applied to find out the consumers wants and needs. The study of consumer behavior helps every common man in all its practical sense. In a competitive environment one cannot thrust a product on the consumers. It is essential for marketers to understand consumers for their own survival and success in competitive marketing environments. The reason for studying consumer behaviour is to find out the role it plays in the lives of many consuming public at large and that as the institutions involved in the production and marketing of different types of consumable articles, equipment, goods and services in general. But for such studies it would be difficult to ascertain the exact needs of consumers.
The consumer has also to take decision about when and where to buy the products that he needs or wants, how much the consumer wants to spend on it, or how much the consumer can afford to and how the consumer will pay for it. Some purchase decisions are routines and may not require these considerations. Other purchase situations may be more complex. In other cases considerations regarding status and prestige are also important. Many product purchases may require the evaluation of a variety of economic, social, and psychological factors. To solve the problems of consumers and marketers, there must be continuous studies in the field of consumer buying behaviors. Few researches have been done in India on the impact of consumer buying behaviour and brand equity on consumer durables. Most of the studies have been considered non-durable products. This study has left a gap in the studies done in durable product sector in India. Hence, this study has been undertaken to consider the research work.

\section{Objectives of The Study}

The specific objectives of the study are

1. To analyse the factors influencing consumers ${ }^{6}$ perception towards purchase behaviour of consumer durable goods in Tiruvarur district.

2. To identify the purchase behavior of selected rural and urban consumer durable goods in Tiruvarur district.

3. To analyse the purchase behaviour and satisfaction of the rural and urban consumer durable goods.

\section{Hypotheses of The Study}

The following hypothesis were framed and tested

Ho1: There is no significant difference between demographic profile and factors influence the consumers ${ }^{6}$ perception towards consumer durable goods.

Ho2: There is no significant difference between demographic profile of respondents and purchasing behaviour of consumer durable goods.

\section{Research Methodology}

The study is based on both primary secondary data. The primary data were collected directly from the sample of consumers through a well-devised interview schedule. Incomplete and inaccurate responses were dropped out, upon the respondents having select five durable goods viz., Air conditioners, Refrigerators, Washing machines, 
Television and Wet grinder as samples for the purpose of the study.

For data collection the researcher visited the respondents at their responds more than once, at their leisure are conveniences. The secondary data relating to the study were collected from books, journals, research articles, magazines, reports, newspapers and websites. The researcher also visited the library of Indian Institute of Management, Bangalore, for the collection of some source materials.

\section{Sampling Design}

The researcher was taken by convenience sampling method. This research based on empirical investigation. The study area has spreads over of Tiruvarur District, Tamil Nadu. To make the samples representative, as far as possible, various steps have been taken into consideration. 145 samples have been selected areas of the Tiruvarur District. This study was selected on the basis of demographic; Socio - economic and cultural status conditions. Five consumer durable products have been selected i.e. Air conditioners, Refrigerators, Washing machines, Television and Wet grinder for this study.

\section{Data Collection}

This research study is primarily an empirical study on the consumer behavior relating to selected consumer durables. The researcher collected information through primary and secondary data, the interview schedule has been constructed to collect data from consumers of Tiruvarur District towards information related to consumer durable goods, with the demographic; socio-economic and cultural conditions of consumer. The secondary data has also been collected from different sources of journals, magazines, annual reports, internet; books related to topic, etc. the data analysis has been conducted with the following methods.

\section{Sample Selection}

The researcher was adopted convenience sampling method. The respondents chosen from an age group residing in Tiruvarur in age group of 20 - 65 Years including the different strata of consumer durable goods. 200 interview schedules were conducted to the respondents spread over in Tiruvarur district. Among them 166 interview schedule were collected. In which 21 interview schedule were found unusable. Hence, the accurate sample of the study is 145 . The method of collection is substantiated in the following table 1 .

\section{Table 1 Selection of Sample Distribution}

\begin{tabular}{|c|c|c|c|c|c|}
\hline S.No & Particulars & Circulated & Received & Rejected & Accounted \\
\hline 1 & Iluppur & 20 & 18 & 02 & 16 \\
\hline 2 & Aranthangi & 20 & 17 & 03 & 14 \\
\hline 3 & Alangudi & 20 & 15 & 01 & 14 \\
\hline 4 & Kulathur & 20 & 16 & 04 & 12 \\
\hline 5 & Thirumayam 2 & 20 & 14 & 03 & 11 \\
\hline 6 & Karambakudi & 20 & 19 & 01 & 18 \\
\hline 7 & Ponnamaravathi & 20 & 18 & 02 & 16 \\
\hline 8 & Gandarvakkottai & 20 & 16 & 02 & 14 \\
\hline 9 & Avudayarkoil & 20 & 18 & 02 & 16 \\
\hline 10 & Iluppur & 20 & 15 & 01 & 14 \\
\hline Total & & 1200 & 166 & 21 & 145 \\
\hline
\end{tabular}

Source: Primary Data

\section{Statistics Tools And Framework Of Analysis}

In order to consumer behavior, Percentage analysis, Descriptive analysis, Kruskal Wallis test, t-test, ChiSquare Test, Analysis of one way ANOVA, Regression Analysis, Factor analysis and Reliability test were employed.

\section{Tabulation}

Primary data from the respondents are presented in the bi-variate, univariate, one-way and Cross tabulation is prepared which is used full of the data analysis. Tabulation makes percentage analysis easier.

- Percentage Analysis It is very power full tool for the data analysis and specifically to understand market share of various companies and average expenses made for consumer durables and other aspects can be measured with this tool. Percentage analysis can wipe out the effect of inflation in measuring consumer behavior.

- One sample $\mathbf{T}$ - test is applied to analyze the respondent's preferences on various elements of purchase decision process in respect of durables.

- Factor analysis by principle component method is applied to analyse the various elements of purchase decision process in respect of durables.

- One-way analysis of variance (ANOVA) is used to identify the significant differences among the various elements of buying behaviour with regard to durables.

- Paired sample $\mathbf{t}$ - test is used to find the mean values of various elements of buying behavior of consumers in respect of durables. 
- Chi - square test is employed to find the association between clusters of buyers of durables and various demographic characteristics. and

- Karl Pearson's coefficient of correlation is used to find the relationship between the variables of the study.

\section{Pilot Study}

The study used a structured interview schedule. The interview schedule was pretested during the months from September 2017 to December 2017 on a sample of 50 consumer selected in Tiruvarur District. A pilot study was undertaken to identify and eliminate ambiguous terms and to check the reliability of the questions. Necessary changes were made in the instrument of the basis of responses to the interview schedule.

\section{Operational Concept}

\section{Consumer Decision Making}

A Process by which consumers identify their needs, collect information, evaluate alternatives, and make the purchase decision. These actions are determined by psychological and economical factors, and are influences by environmental factors such as cultural, group and social values.

\section{Consumer Durable Goods}

Consumer durable products are things that can be used for a long period of time as they are not easily destroyed, Examples of durable goods include; household appliances, machinery and sports equipment.

\section{Purchase Behaviour}

Purchase is to fully pay for a good or service to that good being delivered or service being performed. To fulfill this usage; however, the connotation of the word has started to shift to indicate a purchaser that is not creditworthy.

\section{Limitations Of The Study}

This study has been selected in Tiruvarur District, Tamil Nadu state, India. Due to the diversity of the locations and lack of awareness researcher was not able to collect reliable data. This study is mainly focused on consumer durable goods like Air conditioner, Refrigerator, Television Washing machines and Wet grinder only. This research study is restricted to Tiruvarur District. The household survey has been restricted to a sample size of 145 . The decision on the sample size was rather arbitrary, although the sample size is deemed sufficient considering the nature of the issues analyzed and the requirement of category-wise analysis. The numbers of respondents from different sections of society are not selected in proportionate with the actual number of families in these sections. Only households possessing at least one of the durables under study had been included among the sample households. This has perhaps resulted in excluding those lower class families which do not possess any of the durables selected.

\section{Suggestions}

The following suggestions are made on the basis of the study under various heads.

- A manufacturer may prudently aim at capturing all the income groups of consumers.

- Reliable advertisements may be made to attract the consumers. The manufacturers have to give reliable information to the consumers.

- Interest free installment methods would help to increase the sales of the manufacturers.

- If payments of consumers' durable goods are accepted on installment basis it would help in boosting sales up.

- Service during warranty period is mostly availed by the consumers and if done properly they are satisfied. But some of them have not availed the facility. Hence, door service may be tried for those who want it.

- Quality and brand name are two important factors, which are considered purchasing durable goods. Hence, companies have to provide quality products and they have tried to build brand name.

- The manufacturer may start authorized offer sales and service centers for all brands.

- Product improvement is very important in consumer' durable goods. If the firm continuous to make the product, it may be required to the improvement in its production or distribution so as to yield adequate returns.

- Product presentation need to present based on age as youngsters do not want to have risk after purchase. Elders want to have social status because of the product.

\section{Conclusion}

It may be observed that consumers durable goods is all important products but available for all. In the present study due importance has been attached to the factors like aggressiveness, level of expectation and level of satisfaction and so on. This study has a special feature that the level of expectation for the 
various aspects which characterize the quality and standard of the product are individually taken up. This study also indicates the level of importance attached to the various quality characteristics of the product by the different segments of consumers, who differ in economic, educational, emotional and other characteristics. The demographic variables of the consumers are not deeply associated to their attribute awareness of the product. Brand loyalty is not sufficiently found among the consumers durable goods. They expect good satisfaction from the brand they purchase. They have inclination to change brand to acquire more benefits from the product. It is now realized that one of the steps for providing effective and responsive government is to ensure greater achievement in administration and information to the public. Such an approach would make the study more technical and sophisticated. This kind of an approach will guide the adoption of new types of marketing strategies as well as product refinement, so that the market share can be improved and that was the very purpose of the study.

\section{References}

[1] Carole P. and Duhaims, -Consumer Satisfaction with the Distribution System for DurableProductsll, Journal of Consumer Satisfaction, Dissatisfaction and Complaining Behaviour, Vol.1, 1988, pp.53-59.

[2] Madhavi C. and John William Falix, "Consumers level of Perception and Experience of Product Values with Reference to Refrigeratorsll, Indian Journal of Marketing, Vol.XXXII, No.10, October 2002, pp.6-8.

[3] Margaret Craig-Less, "Consumer Behaviour, Consumer Goods, Image, Marketing, Productsll, Journal of Product and Brand Management, 1998, Issue.6, pp.34-37.

[4] Markarand Upadhyaya and Swati Soni, "Consumer Behaviour and online Marketing, Indian Journal of Marketing, Vol.XXXII, No.10, October 2002, pp.22-23.

[5] Mary C. Gilly Betsy D. Gelb, "Post-Purchase Consumer Processes and the Complaining Consumerll, Journal of Consumer Research, Vol.9, No.3, December 1982, pp.323-328.

[6] Minna Mattila, Consumer Behaviour: Factors Affecting the Adoption of Mobile Marketing Servicesll, The ICFAI Journal of Services Marketing, September 2002, pp.56-78.
[7] Parveen S. goel and Nanua Sigh, -Creativity and Innovation in Durable Product Developmentl, International Conference on Computers and Industrial Engineering, Vol.35, 1998, pp.5-8.

[8] Ramachandran Azhagaiah and Eganathan Ezhilarasi, -Consumer Behaviour Regarding Durable Goodsl, Indian journal of Marketing, Vol.42, No.2, February 2012, pp.27-39. 